\title{
Secondary Syphilis in Human Immunodeficiency Virus (HIV)-Infected Men Who Have Sex with Men (MSM): A Case Report
}

\author{
Ade Fernandes, Evy Ervianti \\ Departement of Dermatology and Venereology \\ Faculty of Medicine Universitas Airlangga/Dr. Soetomo General Academic Teaching Hospital \\ Surabaya
}

\begin{abstract}
Background: Recently, the incidence of syphilis among men who have sex with men (MSM) has increased rapidly, especially among Human Immunodeficiency Virus (HIV)-infected MSM. Coinfection with these two organisms alter the symptoms and signs, progression of the disease, and the risk of progressing to the tertiary stage. Purpose: To report a case of secondary syphilis in HIV-infected MSM. Case: A 24-year-old male complaint of multiple redness macule for 1-month duration on his chest, back, groin, palm, and soles. The rash was neither painful nor pruritic. He also complains of hair los s resulting "moth eaten" alopecia. One month before, he had a painless ulcer on his genital, which resolved without treatment. His HIV infection was diagnosed two years earlier. He had been sexually active with multiple homosexual partners without using a condom since 2010. The Venereal Disease Research Laboratory test (VDRL) titer was 1/32, and Treponema pallidum haemagglutination assay (TPHA) was 1/20480. Initial treatment was a single dose of 2.4 million units of benzathine penicillin. Serologic examination was reevaluated on month 1, 3, 6, and 9 after therapy and declined in the third month. Discussion: For HIV-infected persons, the clinical manifestations of syphilis in most of the cases remain the same. However, the lesions are more aggressive, and coexistence of primary and secondary syphilis is more frequent. Serologic tests are accurate and reliable for the diagnosis and for following a patient's response to treatment. Penicillin is effective but physical and serological follow up is needed. Conclusion: HIV-infected MSM have higher risk of syphilis. Staging is needed to determine the treatment. Serologic examination should be repeated and long enough to monitor the treatment success.
\end{abstract}

Key words: Secondary syphilis, HIV coinfection, MSM.

Correspondence address: Evy Ervianti, Department of Dermatology and Venereology, Faculty of Medicine, Universitas Airlangga, Dr. Soetomo General Academic Teaching Hospital, Jl. Prof. Dr. Moestopo Street No. 6-8 Surabaya 60131, Indonesia. Phone number:+6231-5501609, e-mail: evy_if@yahoo.co.id.

\section{INTRODUCTION}

Syphilis is a chronic, systemic infection caused by Treponema pallidum subspecies pallidum. It has been called the "great imitator" in reference to its ability to cause a wide range of manifestations in nearly every organ system. It is acquired by direct contact, usually sexual, with active primary or secondary lesions. Studies have shown that 16-30\% of individuals who have had sexual contact with syphilis infected person in the preceding 30 days become infected, and in some cases, the transmission rates may be much higher. ${ }^{1,2}$

Syphilis and Human Immunodeficiency Virus (HIV) have played an important role in public health. These two infections overlap, interact, and share significant characteristics. HIV-syphilis co-infection is often cited as a major reason behind recent resurgence in syphilis prevalence among men who have sex with men (MSM). Syphilis incidence among MSM has been on the rise globally in the last years. Particularly in western countries, sharp increases in numbers of syphilis infections were observed. This increase was mainly due to a rise in the number of newly diagnosed cases in MSM. In Germany, the number of reported syphilis cases increased between $11 \%$ and $22 \%$ per year between 2010 and 2014. As of 1 March 2016, 54.747 newly diagnosed cases of syphilis had been notified in Germany between 1 January 2001 and 31 December 2015, with cases increasing since 2010. In 2015, 6.834 cases were reported, corresponding to a $19.4 \%$ increase compared with 2014. Men accounted for $93.8 \%$ of cases in 2015 $(\mathrm{n}=6.834)$. The transmission route was reported for $75.6 \%$ of cases $(n=5.166)$; of these, $84.7 \%$ occurred in MSM, $15.0 \%$ among heterosexual persons, and $0.3 \%$ were acquired through other routes of transmission. The increasing trend was almost entirely based on respondents with HIV. Between 2003 and 2013, the proportion of MSM diagnosed with HIV (n $=1.934$ ) reporting newly diagnosed syphilis, increased from $9.3 \%$ to $19.0 \%$, while the proportion of MSM not diagnosed with HIV $(n=9.397)$ and self- 
reporting a recent syphilis diagnosis, fluctuated between $1.7 \%$ and $2.7 \%$. $^{2,3,4}$

Despite more than a decade of HIV-prevention efforts, there is currently no evidence of reduced HIV prevalence among MSM in Indonesia. An analysis of 2011 Integrated Biological and Behavior Survey reported that HIV prevalence among MSM rose from $5 \%$ in 2007 to $12 \%$ in 2011. Furthermore, HIV prevalence differs across geographic areas in Indonesia. According to Morineau et al in 2011, HIV and syphilis prevalence among MSM in Surabaya was $5.6 \%$ and $4 \%$ respectively. ${ }^{5,6}$

The course of untreated syphilis consists of intermittent stages with sequential symptomatic and asymptomatic periods. The stages of untreated syphilis can be classified into primary syphilis, secondary syphilis, latent syphilis, and tertiary syphilis. This regular choreography, however, may be disturbed if the immunological competence of the host organism is severely compromised (HIV infection) by inappropriately administered prevention or antimicrobial therapy for another disease. These may modify or change the time of presentation, the character of symptoms and signs, the progression of the disease, and the risk of progressing to the tertiary stage. $^{2}$

We report a case of secondary syphilis in an MSM patient with HIV coinfection. This case reveals a specific dermatological lesion of secondary syphilis and confirmed by serological testing. This report discusses the clinical presentation, diagnosis, treatment, and serological response.

\section{CASE REPORT}

A 24-year-old male came to the outpatient clinic on $18^{\text {th }}$ May 2016, complaining multiple redness patches of 1-months duration. At first, the lesion had appeared on his abdomen, then had spread to his entire body and also increased in size. The rash involved chest, back, groin, including the palm and soles. The rash was neither painful nor pruritic and had changed minimally since its onset. He also complained about severe hair loss distributed over the whole scalp co-occurring with an eruption of red macule on his body. During the first week of the rash, he visited a clinic where he was prescribed a topical steroid cream and topical antifungal cream. However, there was no improvement after two weeks of application of the medicine. One month before the rash appeared, he had a painless ulcer on his genital, which resolved without treatment. His past medical history included HIV diagnosed two years earlier. The patient started antiretroviral therapy two years before the current presentation, and he routinely attends check-up visits to Bhayangkara Hospital. The baseline CD4 was 168 cells/ $\mu \mathrm{L}$. The patient was unmarried, however, reportedly had been sexually active with multiple homosexual partners without using a condom since 2010 . He had a history of unprotected sexual intercourse for the last three months prior to the genital ulcer. Sometimes he met sexual partners on social media. He denied if the partner had the same symptoms. There was no history of consuming drugs before the lesions appeared, drug hypersensitivity, blood transfusion, injection drug use, or drug abuse. History of fever, headache, malaise, diarrhea, weight loss was denied.

Physical examination of the general state showed the blood pressure was $110 / 80 \mathrm{mmHg}$, pulse rate was 86 times per minute, respiratory rate was 18 times per minute, and body temperature was $36.6^{\circ} \mathrm{C}$. From head and neck, there were no signs of anemia, cyanosis, icterus, or dyspnea. Thorax examination of heart and lungs were concluded normal. Abdomen, liver, and spleen were not palpable. On his upper and lower extremities, there was no edema and warm on palpation. There was no enlargement of the cervical, axillar, inguinal, and genital lymph nodes.

Dermatological examination on thoracalis anterior et posterior, scalp, palmar manus dextra, plantar pedis dextra et sinistra region, found that there were multiple violaceous macules, sharply marginated, vary in size, and covered with thin scales. There was the 'moth-eaten' syphilitic alopecia. There was hyperpigmented macule, unsharply marginated on the genital area. No evidence of lip or buccal mucosal lesions were noted.

The laboratory examination on $18^{\text {th }}$ May 2016 revealed: hemoglobin was $13.7 \mathrm{~g} / \mathrm{dL}$, white blood count $6.090 / \mathrm{mm}^{3}$, thrombocyte $218.000 / \mathrm{L}$, Hct $38.2 \%$. The urinalysis results were within normal limits. The serology titer of Venereal Disease Research Laboratory test (VDRL) titer was 1:32, and Treponema pallidum haemagglutination assay (TPHA) was 1:20480 with CD4 count 88 cells/ $\mu \mathrm{L}$. Potassium hydroxide examination samples were collected from the rash on the inguinal and thoracalis anterior region and resulted in a negative result. The patient was treated with a single dose of 2.4 million units of benzathine penicillin intramuscular. Two weeks after treatment completion, the violaceous macule became hyperpigmented macule covered with thin scales. There was no lymph node enlargement. We repeated serologic tests for syphilis one month after the therapy completed. The results for VDRL remained the same with 1:32 and TPHA 1:20480. We did not repeat the therapy for syphilis and continued to observe the syphilis serology. 


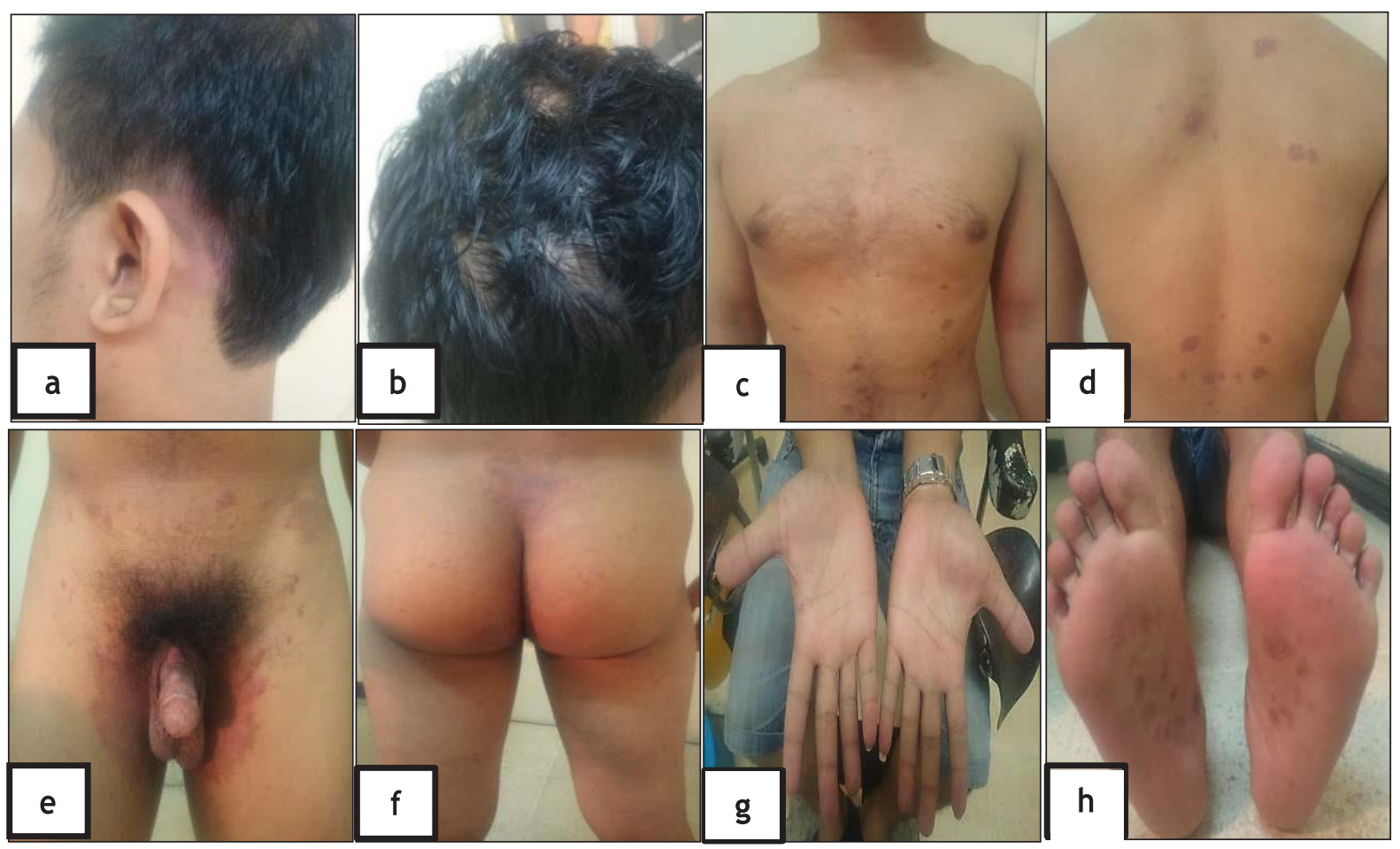

Figure 1. The clinical manifestation before treatment; on scalp region (a,b), there were 'moth-eaten' syphilitic alopecia; on thoracalis anterior et posterior, scalp, palmar manus dextra, plantar pedis region $(\mathrm{c}, \mathrm{d}, \mathrm{f}, \mathrm{g}, \mathrm{h})$, there were multiple violaceous macules, sharply marginated, vary in size, and covered with thin scales; on inguinal region (e), there were erythematous macule, sharply marginated, and covered with thin scale. $\mathrm{KOH}(-)$, Wood's light (-).

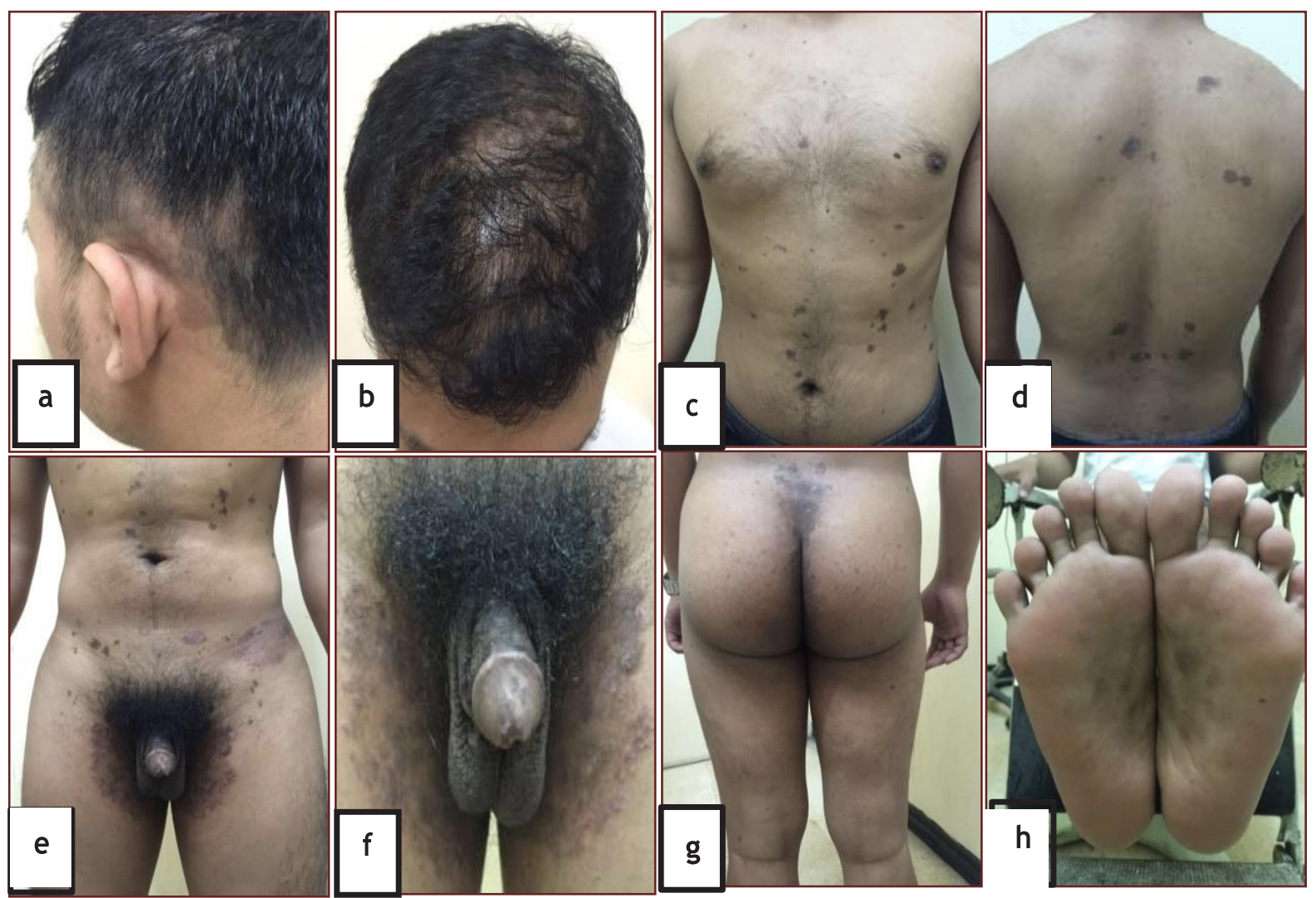

Figure 2. The clinical manifestation one month after treatment completion; on scalp region $(\mathrm{a}, \mathrm{b})$, there were 'moth-eaten' syphilitic alopecia; on thoracalis anterior et posterior, inguinal, plantar pedis dextra et sinistra region (c,d,e,f,g,h), there were multiple hyperpigmented macules, sharply marginated, vary in size, and covered with thin scales. 


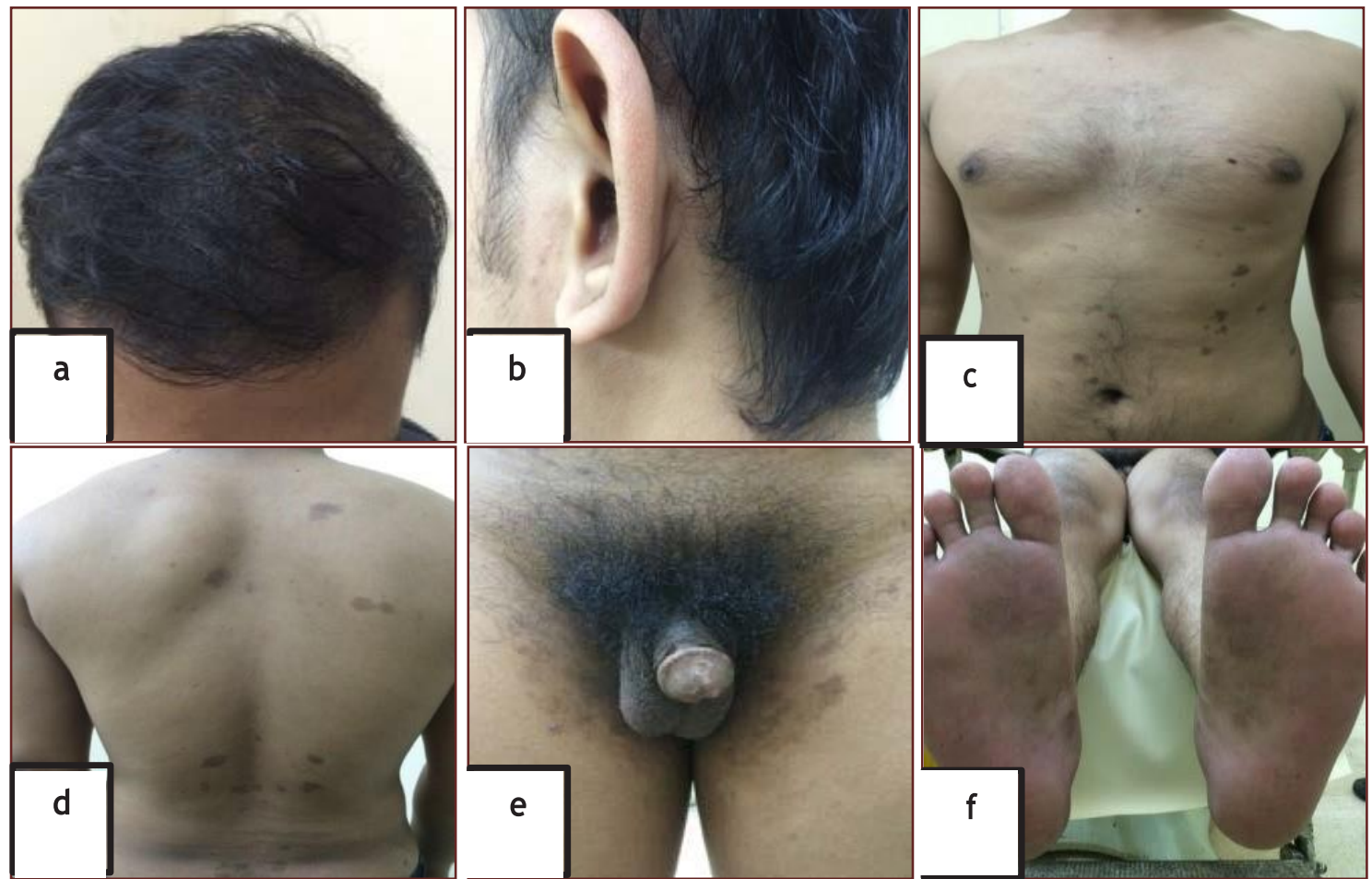

Figure 3. The clinical manifestation three months after treatment completion; scalp region $(a, b)$ showed regrowth of hair.; on thoracalis anterior et posterior, inguinal, plantar pedis dextra et sinistra region $(\mathrm{c}, \mathrm{d}, \mathrm{e}, \mathrm{f})$, there were multiple hyperpigmented macules, sharply marginated, and vary in size.

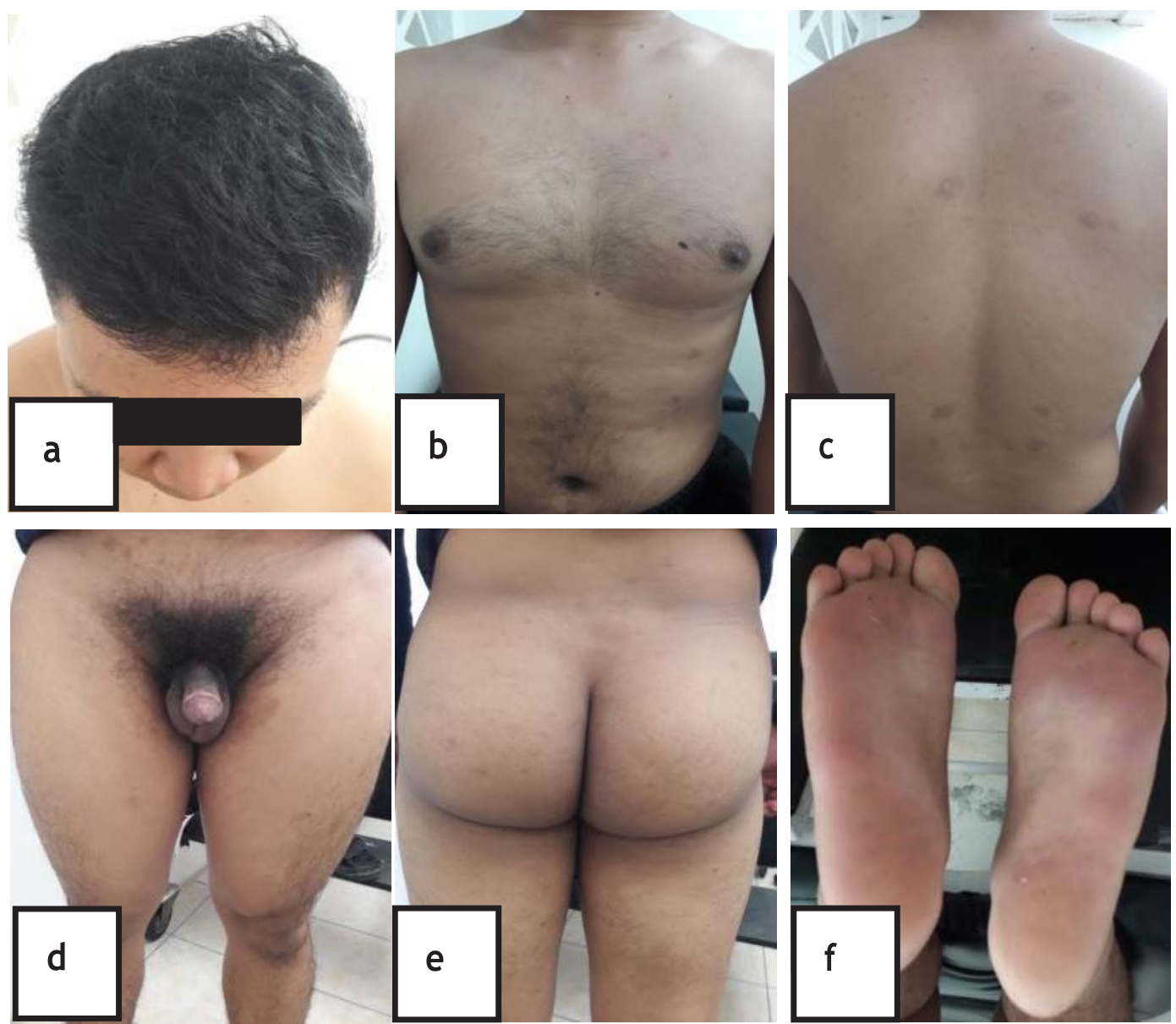

Figure 4. The clinical manifestation six months after treatment completion; scalp region (a) showed regrowth of hair; on thoracalis anterior et posterior, inguinal, plantar pedis dextra et sinistra region (b,c,d,e,), there were multiple hyperpigmented macules, unsharply marginated. 
Three months after the end of the antibiotic therapy, the VDRL declined to $1: 16$, and TPHA remained the same at 1:20480. The CD4 count three months after the commencement of treatment showed 184 cells $/ \mu \mathrm{L}$, indicating a positive response to the treatment. Six months after therapy, VDRL titer declined to 1:8, and TPHA titer was 1:10240. Nine months after therapy, the VDRL titer declined to 1:4, and TPHA titer was 1:5120. The serologic examination was reevaluated on month $1,3,6$, and 9 after therapy completion to ensure a reduction in nontreponemal antibody and to confirm the treatment response.

\section{DISCUSSION}

Syphilis infections have increased in recent years internationally, especially among MSM. The surge in syphilis among MSM is troubling, considering the morbidity associated with untreated syphilis, including neurosyphilis and cardiovascular sequelae. Furthermore, syphilis is associated with both HIV transmission and acquisition, and a disproportionate number of syphilis diagnoses occur in HIV infected MSM. $^{7}$

The term "men who have sex with men" (MSM) describes a heterogeneous group of men who have varied behaviors, identities, and health care needs. Some MSMs are at high risk for HIV infection and other viral and bacterial STDs because MSM may practice anal sex, and rectal mucosa is uniquely susceptible to certain STD pathogens. In addition, factors that increase the risk for HIV infection in MSM include either receptive or insertive anal sex without a condom, having another STD, having sex with anonymous partners without using condom, and using methamphetamines to decrease inhibitions, increase sexual pleasure, and increase the likelihood of engaging in condomless sex or drugs that enhance sexual performance. Factors associated with increases in syphilis among MSM have included substance abuse, having multiple anonymous partners, and meeting sex partners on the internet or geosocial networking applications, HIV serosorting, substance use, and erectile dysfunction medication use. They are all identified risk factors for syphilis or other sexually transmitted infections among MSM. Our case here showed syphilis and HIV co-infection in a 24-year-old male. Sexual behavior is perhaps related to the transmission of syphilis such as seeking sex partner on social media, having multiple anonymous male partners without using condom and HIV condition. ${ }^{8,9,10}$

Syphilis is a highly infectious sexually transmitted disease (STD) caused by Treponema pallidum subspecies pallidum. It is a systemic disease characterized by symptomatic periods alternating with periods of clinical latency, which results in a wide variety of clinical presentations. Classically, syphilis infection has been divided into primary, secondary, latent, and tertiary stages. The clinical manifestations of syphilis in HIV patients can be very similar to those seen in an otherwise healthy host. However, coinfection with these two organisms may also alter the symptoms and signs, the progression of the disease, and the risk of progressing to the tertiary stage. $^{2}$

Clinical manifestation of syphilis is not affected very much in HIV-infected populations. Thus, the manifestation is almost similar to those without HIV infection. However, there are some differences that can be seen in HIV-infected patients. As defined by CDC surveillance case definitions, primary syphilis is a stage of syphilis characterized by one or more chancres, in the presence of laboratory evidence from tissues or sera consistent with syphilis. At the inoculation site, a chancre develops after an incubation period that ranges from 10 to 90 days (three weeks on average) and is associated with painless regional lymphadenopathy arises 7-10 days after the chancre appears, especially for chancre located at the genital. Unilateral lymphadenopathy is more common earlier in the course of disease with bilateral involvement later in the course. This chancre is a unique, firm, usually painless, non-purulent, indurated, round ulcer located in the inoculation area. It initially presents as a small papule that ulcerates very rapidly. Genital ulcers primarily increase the transmission of HIV caused by the loss of the epidermal barrier and local inflammation. Some studies have reported that syphilis increases viral replication, viral shedding, and the viral load in the seminal fluid in HIV patients. Additionally, syphilis co-infection among HIV patients can increase the concentration of HIV RNA in blood plasma and decrease the number of CD4+ T cell counts and may increase the risk for HIV transmission. Syphilis has been estimated to increase HIV transmission two to ninefold, and HIV acquisition two to fourfold. In HIV-positive patients, primary syphilis can present with multiple ulcers that are similar to herpetic lesions (soft chancre). These lesions are deeper, persist longer, may leave a scar upon healing, and may lead to perforations in the prepuce or labia majora. Some authors have described the presence of a chancre (primary syphilis) and clinical manifestations of secondary syphilis simultaneously. In patients coinfected with HIV, the lesions may be localized in the mouth and pharynx due to oral sex. The chancre heals in 3-6 weeks 
without treatment and 1-2 weeks with treatment. ${ }^{2,11,12,13}$

Secondary syphilis is a stage of syphilis characterized by localized or diffuse mucocutaneous lesions, often with generalized lymphadenopathy, in the presence of laboratory evidence from tissues or sera consistent with syphilis. Secondary syphilis, which occurs in roughly one-fourth of all untreated syphilis cases, results from the multiplication of disseminated T. pallidum and formation of lesions at multiple sites in the skin and internal organs, despite the presence of a significant antibody response. The diverse manifestations of human syphilis also demonstrate the invasiveness of $T$. pallidum. Secondary syphilis presents after hematogenous dissemination from the chancre has occurred, usually 4-10 weeks after the appearance of the primary chancre in the immunocompetent patient. It usually manifests as mucocutaneous lesions with systemic symptoms. However, $75 \%$ of coinfected HIV patients present with secondary syphilis while the chancre is still present. Systemic symptoms include fever, anorexia, muscle pain, depression, arthritis, and weight loss. Mucocutaneous lesions typically present as generalized, nonpruritic, symmetric, oval, violaceous, pink or coppery brown macules were varying in size from 1 to $20 \mathrm{~mm}$ with the involvement of the palms and soles. Without treatment, the secondary stage typically recedes in 4-12 weeks. ${ }^{2}$ In this case, we noted that the patient presented with a genital ulcer followed by a rash on his body, palm, and soles simultaneously. This situation is observed more common in HIV infected persons than those without HIV.
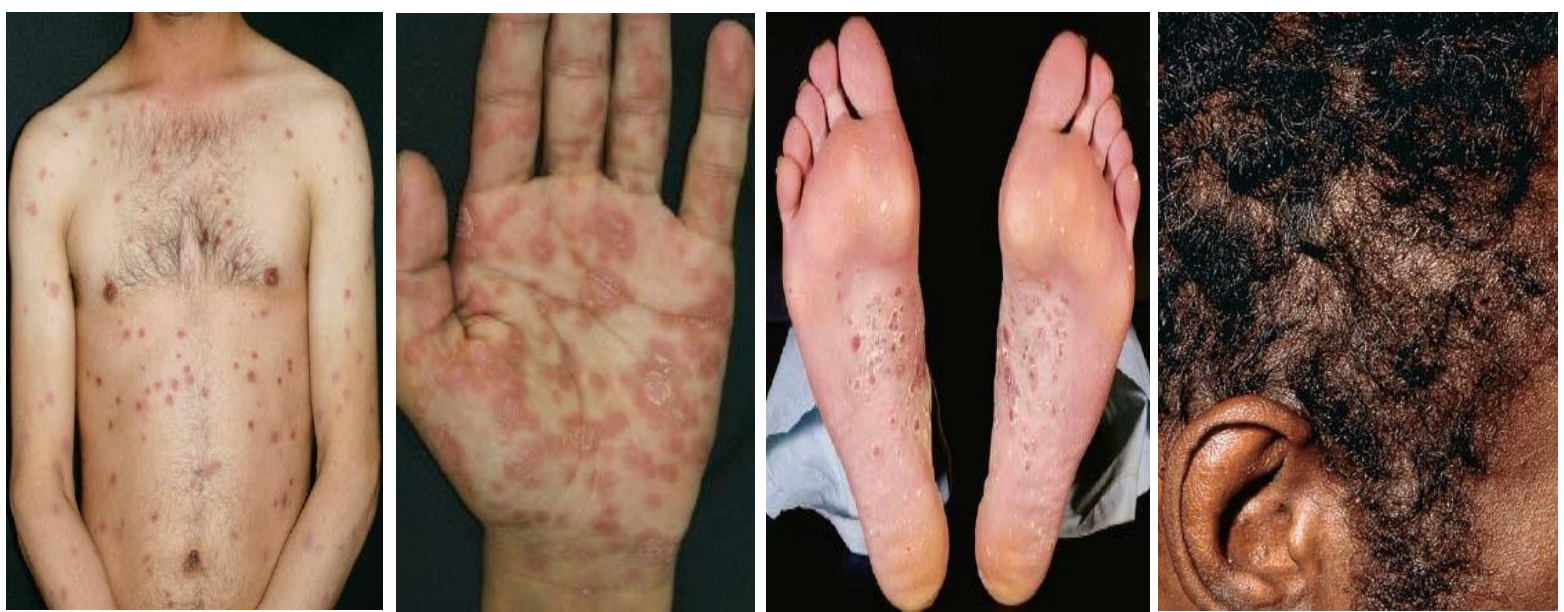

Figure 5. Secondary syphilis: oval, violaceous, pink or coppery brown macules involving the trunk, palms and soles and moth-eaten alopecia., ${ }^{2,11}$

The scalp may be involved, resulting in alopecia. The eyebrows and beard area can be affected too. The 'moth-eaten' pattern is the most frequent clinical manifestation of syphilitic alopecia (SA) and represents one of the most characteristic signs of secondary syphilis. In the event of suspected secondary syphilis, the patient should be examined for the presence of signs compatible with SA, questioning about any perceived sign of hair loss or alopecia and examining the scalp in the parieto-occipital areas, where these signs are more frequently observed. It is crucial for physicians, and in particular for the dermatologist, to regain the lost ability to recognize the variable manifestations of syphilis even the less known or uncommon ones such as SA. This clinical sign appears to be much more frequent than the reported in the literature and can be a valuable additional element to aid clinician in suspecting a diagnosis of syphilis. We found that the patient had hair loss with the moth-eaten pattern associated with syphilis infection. Hair and scalp abnormalities associated with secondary syphilis observed in our case had completely disappeared eight weeks after the end of therapy. This evolution of SA supports what the literature suggests about its absolute reversibility. ${ }^{2,14}$

For most HIV infected persons, serologic tests are accurate and reliable for the diagnosis of syphilis and for following a patient's response to treatment. Regardless, both treponemal and nontreponemal serologic tests for syphilis can be interpreted in the usual manner for most patients who are coinfected with T. pallidum and HIV. When clinical findings are suggestive of syphilis, but serologic tests are nonreactive, or their interpretation is unclear, alternative tests such as a biopsy of a lesion, dark-field examination, and PCR of lesion material might be useful for diagnosis. Neurosyphilis should be considered in the differential diagnosis of neurologic disease in HIV infected persons. Compared with HIV 
negative patients, HIV positive patients who have early syphilis might be at increased risk for neurologic complications and might have higher rates of serologic treatment failure with currently recommended regimens. The magnitude of these risks is not defined precisely but is likely small. No treatment regimens for syphilis have been demonstrated to be more effective in preventing neurosyphilis in HIV infected patients than the syphilis regimens recommended for HIV negative patients. Careful follow-up after therapy is essential. The use of antiretroviral therapy as per current guidelines might improve clinical outcomes in persons with HIV infection and syphilis. ${ }^{15,16}$

Serologic tests usually do not result positive until after the clinical manifestations have been present for at least three weeks. Direct fluorescent antibodies and polymerase chain reaction (PCR) can be used, especially when the symptoms and the serologic tests are discordant. Dark-field microscopy is the only test that allows immediate diagnosis. The sample must be taken from the lesions, avoiding blood, and read very quickly by an experienced person. The spirochete is identified by its shape and movement. Direct immunofluorescence allows T. pallidum to distinguish from other nonpathogenic treponemas. PCR has a 95$97 \%$ specificity and a $91-95 \%$ sensitivity; however, due to a high cost, it is not commonly used. Some cases require a skin biopsy to visualize the bacteria using a Warthin Starry stain. The most common nonspecific treponema tests used are rapid plasma reagin (RPR) and Venereal Disease Research Laboratory (VDRL). The specific tests include fluorescent treponemal antibody absorption (FTAABS), microhemagglutination test for antibodies to $T$. pallidum (MHA-TP), $T$. pallidum particle agglutination assay (TPPA), Treponema pallidum hemagglutination assay (TPHA). The TPHA can be used in combination with VDRL or RPR to maximize the detection of primary infection on screening. For the majority of the HIV population coinfected with syphilis, laboratory tests can be interpreted as they would be in an immunocompetent host. However, atypical serologic results can occur as false negatives or delayed titer responses. If the serology tests resulted in negative, then skin biopsy, dark-field microscopy, or PCR testing would be necessary to confirm the diagnosis. Serology tests may remain positive despite an appropriate treatment after one year in $18 \%$ of the coinfected population but in only $5 \%$ of the non-HIV infected population. Some studies report cases of seronegativity and return of titers to nonreactive as immunosuppression advances. ${ }^{2}$

In our laboratory examination, we use VDRL titer as a follow-up laboratory test in syphilis following the treatment. Serological failure can be defined as a lack of fourfold decreases in VDRL titers at 6-12 months after therapy for primary or secondary syphilis, signs, or symptoms that persist or recur or persons who have a sustained $>2$ weeks fourfold increase or greater in titer. Increased risk of serological failure has been reported to be more common among those with late stage of syphilis and HIV-infected patients. ${ }^{16}$ In this case, serological failure was not seen after nine months follow up. VDRL titer declined fourfold after 6 months of completed therapy. However, the subsequent followup sample is needed for further confirmation of this condition.

The CDC guidelines for the treatment of primary, secondary, tertiary, and early latent syphilis less than one year in HIV patients are very similar compared to those of HIV-negative patients. Most reports show that HIV infection does not markedly affect response to benzathine penicillin therapy. The U.S. Public Health Service continues to recommend a single dose of 2.4 million units benzathine penicillin in this situation. Penicillin is the antibiotic of choice, and it is a recommended antibiotic in HIV infected population because it can reach a high concentration in the central nervous system for the treatment of neurosyphilis, which is more common in this population. Penicillin remains not only the most effective treponemicide, but it is easy to administer, has few side effects, and is relatively inexpensive. Results continue to be excellent for all forms and stages of treponemal disease, and there are no signs that $T$. pallidum has developed resistance to this antibiotic. Injectable penicillins are generally preferred to oral preparations because of problems of patient compliance and uncertain absorption from the gastrointestinal tract. However, benzathine penicillin may not prevent the progression to early neurosyphilis in HIV infected persons based on numbers of individual cases in which treatment of primary or secondary syphilis with benzathine penicillin was followed by rapid progression to neurosyphilis, along with evidence of persisting treponemes in the Cerebrospinal Fluid (CSF) of HIV-infected patients after treatment. Those who recommend a single dose of benzathine penicillin state that the percentage of fail treated cases is so small that they cannot recommend an increased penicillin dose for everyone. ${ }^{2,12,16,17,18}$ 
Table 6. Treatment of syphilis ${ }^{11}$

CDC Recommendation for Treatment and Follow-up of Adults with Primary, Secondary, or Early Latent Syphilis

$\begin{array}{lll}\text { Stage of } & \text { HIV Status of } & \text { Recommended } \\ \text { Disease } & \text { Person } & \text { Treatment }\end{array}$

\begin{tabular}{|c|c|c|}
\hline $\begin{array}{l}\text { Alternative } \\
\text { Treatment } \\
\text { for Penicillin- } \\
\text { allergic } \\
\text { Persons (Non- } \\
\text { Pregnant } \\
\text { Women Only) }\end{array}$ & $\begin{array}{l}\text { Schedule } \\
\text { for Follow-up } \\
\text { After } \\
\text { Treatment }\end{array}$ & $\begin{array}{l}\text { Timeframe } \\
\text { to Expect } \\
\text { Fourfold } \\
\text { Decline in } \\
\text { Titer }\end{array}$ \\
\hline $\begin{array}{l}\text { Doxycycline } 100 \\
\text { mg orally twice } \\
\text { daily for } 14 \text { days }\end{array}$ & $\begin{array}{l}6 \text { and } 12 \\
\text { months }\end{array}$ & 6-12 months \\
\hline $\begin{array}{l}\text { Doxycycline } 100 \\
\text { mg orally twice } \\
\text { daily for } 14 \text { days }\end{array}$ & $\begin{array}{l}3,6,9,12 \text {, and } \\
24 \\
\text { months }\end{array}$ & 6-12 months \\
\hline
\end{tabular}

\begin{tabular}{|c|c|c|c|c|c|}
\hline $\begin{array}{l}\text { Primary or } \\
\text { secondary }\end{array}$ & $\begin{array}{l}\text { HIV- } \\
\text { uninfected }\end{array}$ & $\begin{array}{l}\text { Benzathine } \\
\text { penicillin } \mathrm{G}, 2.4 \\
\text { million units, } \\
\text { administered } \\
\text { intramuscularly in a } \\
\text { single dose }\end{array}$ & $\begin{array}{l}\text { Doxycycline } 100 \\
\text { mg orally twice } \\
\text { daily for } 14 \text { days }\end{array}$ & $\begin{array}{l}6 \text { and } 12 \\
\text { months }\end{array}$ & $6-12$ months \\
\hline & HIV-infected & $\begin{array}{l}\text { Benzathine } \\
\text { penicillin } \mathrm{G}, 2.4 \\
\text { million units, }\end{array}$ & $\begin{array}{l}\text { Doxycycline } 100 \\
\text { mg orally twice } \\
\text { daily for } 14 \text { days }\end{array}$ & $\begin{array}{l}3,6,9,12 \text {, and } \\
24 \\
\text { months }\end{array}$ & 6-12 months \\
\hline
\end{tabular}
administered intramuscularly in a single dose

\begin{tabular}{|c|c|c|c|c|c|}
\hline Early latent & $\begin{array}{l}\text { HIV- } \\
\text { uninfected }\end{array}$ & $\begin{array}{l}\text { Benzathine } \\
\text { penicillin } \mathrm{G}, 2.4 \\
\text { million units, } \\
\text { administered } \\
\text { intramuscularly in a } \\
\text { single dose }\end{array}$ & $\begin{array}{l}\text { Doxycycline } 100 \\
\text { mg orally twice } \\
\text { daily for } 14 \text { days }\end{array}$ & $\begin{array}{l}6,12, \text { and } 24 \\
\text { months after } \\
\text { treatment }\end{array}$ & $12-24$ months \\
\hline & HIV-infected & $\begin{array}{l}\text { Benzathine } \\
\text { penicillin } \mathrm{G}, 2.4 \\
\text { million units, } \\
\text { administered } \\
\text { intramuscularly in a } \\
\text { single dose }\end{array}$ & $\begin{array}{l}\text { Doxycycline } 100 \\
\text { mg orally twice } \\
\text { daily for } 14 \text { days }\end{array}$ & $\begin{array}{l}6,12,18, \text { and } \\
24 \\
\text { months }\end{array}$ & $12-24$ months \\
\hline
\end{tabular}

Some authorities, in contrast, believe that minimum therapy for primary or secondary infection without neurologic involvement in HIV-infected patients should be three doses each of 2.4 million units benzathine penicillin at weekly intervals. However, there are no data to show that progression to neurosyphilis, the principal concern in this situation, is reduced by the more aggressive therapy. There are no data to support the use of doxycycline in this situation. Azithromycin appears to be equally efficacious in HIV positive and negative subjects, but worries on azithromycin resistance raise serious concerns. Additional reservations about the macrolides stem from the evidence favoring their use in syphilis never was strong, and they plainly do not readily cross the blood-brain barrier. ${ }^{18}$ In our case, the treatment with a single dose of 2.4 million units benzathine penicillin was given according to the stage of syphilis, and the patient recovered well after the treatment by decreasing of the rash on his body, regrowth of hair, and serologic titer fourfold after three months completed therapy.

Patients should be warned of possible reactions to treatment. Facilities for resuscitation should be available in the treatment area. All patients should be kept on clinic premises for 15 minutes after receiving their first injection to observe for immediate adverse reactions. In addition, patients should be advised to seek urgent medical attention if they

experience symptoms or signs of an allergic reaction such as shortness of breath, itchy wheals on their skin, facial swelling, or tightness in their chest or throat. Facilities for the treatment of anaphylaxis should be available. Standard treatment protocols for the management of anaphylactic shock should be followed. ${ }^{19}$

Careful serological and clinical follow-up after treatment is important, especially in the patient with early syphilis who is also HIV infected. Patients must be evaluated for treatment failure at 3, 6, 9, 12, and 24 months after initial therapy. Treatment failure is suggested by a fourfold increase in titers, less than a fourfold decrease in pretreatment titers within 12-24 months, and the development of symptoms or signs attributable to syphilis. Factors associated with treatment failure in HIV disease include a low initial 
serological titer (RPR $<1: 16$ ), a history of prior syphilis, and a CD4 count was less than 350 cells $/ \mathrm{mL}$. CSF and retreatment are considered in patients whose nontreponemal tests do not decrease fourfold within $6-12$ months of therapy. The majority of specialists treat treatment failure with benzathine penicillin G. In this case, the patient was managed similarly to nonHIV infected patients. There was a risk of treatment failure of this patient since the CD4 count was only 88 cells $/ \mathrm{mL}$. Furthermore, efficient education including safer sexual behavioral interventions are urgently needed to reduce the risk for Sexually Transmitted Infection (STI) transmission among HIV patient and recurrence of syphilis. ${ }^{2,13,17,20}$

It is recommended that attempts be made to identify, trace, and offer further investigation to atrisk sexual contacts. In early syphilis, these are contacts occurring within three months plus the duration of symptoms for primary syphilis, within six months plus the duration of symptoms for secondary syphilis and within one year for the early latent disease. All long-term partners of patients with late syphilis should be offered investigation. The treatment of sexual partners is based on their clinical and serologic findings. If they are seronegative but had exposures as previously outlined, treatment would be as for early syphilis, with benzathine penicillin, 2.4 MU intramuscularly as one dose. In this case, the history of many sexual contacts met in social media caused difficulty in sexual partner management. Service links with high- risk places to provide screening and advice may prove useful. . $^{17,19,20}$

The cure rates with initial treatment of early syphilis are higher than $95 \%$. The long-term outcome of adequately treated cases is excellent. In late syphilis, an infection can usually be arrested, although some treponemes may persist in less accessible sites (e.g., the eye and nervous system). As long as immune function is normal, this rarely has clinical sequelae. The prognosis of HIV positive appears to be less assured. However, long-term evaluation in this patient is needed. ${ }^{17}$

\section{REFERENCES}

1. Holman KM, Goepfert A. Syphilis infection in women. In: Beigi RH, editor. Sexually transmitted diseases. London: Wiley-Blackwell; 2012. p. 36-43.

2. Mendoza N, Motta A, Ravanfar PP, Tyring SK. Syphilis and HIV. In: Gross G,Tyring SK, editors. Sexually transmitted infections and sexually transmitted diseases. London: Springer; 2011. p.173-82.

3. Das A, Li J, Zhong F, Ouyang L, Mahapatra T,
Tang W, et al. Factors associated with HIV and syphilis co-infection among men who have sex with men in seven Chinese cities. Int J STD AIDS 2015; 26(3):45-55.

4. Jansen K, Schmidt AJ, Drewes J, Bremer V, Marcus U. Increased incidence of syphilis in men who have sex with men and risk management strategies, Germany, 2015. Euro Surveill 2016; 21(43):1-7.

5. Ministry of Health of the Republic Indonesia. Report on integrated biological- behavioral surveillance of most-at-risk groups (MARG). Jakarta: Directorate General of Communicable Disease Control and Environmental Health; 2012.

6. Morineau G, Nugrahini N, Riono P, Nurhayati, Girault P, Mustikawati DE, Magnani

R. Sexual risk taking, STI and HIV prevalence among men who have sex with men in six Indonesian cities. AIDS Behav 2011; 15(5):1033-44.

7. Petrosky E, Fanfair RN, Toevs K, DeSilva M, Schafer S, Hedberg K, et al. Early syphilis among men who have sex with men in the US Pacific Northwest, 2008-2013: clinical management and implications for prevention. AIDS Patient Care STDS 2016; 30(3):134-40.

8. Jain J, Santos GM, Scheer S, Gibson S, Crouch $\mathrm{PC}$, Khon R, et al. Rates and correlates of syphilis reinfection in men who have sex with men. LGBT Health; 2016:1-7.

9. Solomon M, Mayer KH. Evolution of the syphilis epidemic among men who have sex with men. Sex Health 2015; 12(2):96-102.

10. Sánchez-Gómez A, Jacobson JO, Montoya O, Magallanes D, Bajaña $\mathrm{W}$, Aviles O, et al. HIV, STI and behavioral risk among men who have sex with men in a setting of elevated HIV prevalence along Ecuador's Pacific Coast. AIDS Behav 2015; 19(9):1609-18.

11. Katz KA. Syphilis. In: Goldsmith LA, Katz SI, Gilchrest BA, Paller AS, Leffell DJ, Wolff K, editors. Fitzpatrick's Dermatology in general medicine. $8^{\text {th }}$ ed. New York: McGraw Hill; 2012. p. 2471-92.

12. Wahab AA, Rahman MM, Mohammad M, Hussin S. Case series of syphilis and HIV coinfections. Pak J Med Sci 2013; 29(3):856-58.

13. Hu QH, Xu JJ, Zou HC, Liu J, Zhang J, Ding $\mathrm{HB}$, et al. Risk factors associated with prevalent and incident syphilis among an HIV-infected cohort in Northeast China. BMC Infectious Diseases 2014; 14:658-68. 
14. Piraccini BM, Broccoli A, Starace M, Gaspari V, D'Antuono A, Dika E, et al. Hair and scalp manifestations in secondary syphilis: epidemiology, clinical features and trichoscopy. Dermatology 2015; 231(2):171-6.

15. Waugh MA. Syphilis. In: Katsambas AD, Lotti TM, Dessinioti C, D'Erme AM, editors. European handbook of dermatological treatments. $3^{\text {rd }}$ ed. New York: Springer; 2015. p. 931-48.

16. Centers for Disease Control and Prevention. Syphilis. Sexually Transmitted Diseases Treatment Guidelines 2015. MMWR 2015; 64(3):34-48.

17. Kinghorn GR, Omer R. Syphilis and Congenital Syphilis,. In: Griffifths CEM, Barker J, Bleiker $\mathrm{T}$, Chalmer R, editors. Rook's Textbook of dermatology. $9^{\text {th }}$ ed. London: Wiley blackwell; 2016.
18. Lukehart SA Sparling PF, Swartz MN, Musher DM, Healy BP. Clinical manifestations of syphilis. In: Holmes KK, Sparling PF, Stamm WE, Piot P, Wasserheit JN, Corey L, Cohen MS, Watts DH, editors. Sexual transmitted disease. $4^{\text {th }}$ ed. New York: Mc Graw Hill Medical; 2008. p. 661-84.

19. Kingston M, French $\mathrm{P}$, Higgins S, McQuillan O, Sukthankar A, Stott C, et al. UK national guidelines on the management of syphilis 2015 . Int J STD AIDS 2015; 27(6):421-46.

20. James WD, Berger T, Elston DM. Syphilis, yaws, bejel, and pinta. James WD, Berger $\mathrm{T}$, Elston DM. Andrews' Diseases of the Skin, Clinical Dermatology. $12^{\text {th }}$ ed. Philadelphia: Elsevier; 2016. p. 343-55. 